\title{
DENÚNCIAS POR ERRO MÉDICO EM GOIÁS
}

Reginaldo Raimundo Fujita*1, Ilian Cardoso dos Santos ${ }^{2}$

Trabalho elaborado na Instituição: Unifesp-EPM, Programa de Pós-Graduação em Otorrinolaringologia e Cirurgia de Cabeça e Pescoço.

*Correspondência:

Rua dos Otonis, 700

$1^{\circ}$ andar

São Paulo - SP

CEP 04025-001

fujitarc@uol.com.br

\section{RESUMO}

OBjetivo. O fortalecimento da cidadania reforça os instrumentos de defesa dos direitos individuais. Os atuais modelos de atenção à saúde minimizam a comunicação entre médicos e pacientes. Cresce o número de queixas formalizadas contra atitudes médicas. É grande o impacto social dessas denúncias. Faltam estudos, no Brasil e em Goiás, que Ihes dêem significado. Este trabalho pretende quantificar e qualificar as reclamações apresentadas ao Conselho Regional de Medicina de Goiás contra médicos.

Métodos. Estudo descritivo, retrospectivo, sobre as denúncias formalizadas em Goiás, entre 2000 e 2006. Leitura interpretativa da evolução processual das queixas ajuizadas no Conselho e cálculo da eficácia das ações dali decorrentes.

Resultados. Não foi grande a flutuação na frequência de reclamações entre 2000 e 2006; 62\% das queixas alegaram incompetência do profissional e inadequada relação médico/paciente. 0 número de queixas em cirurgia plástica e ortopedia são iguais a $50 \%$ dos especialistas. Houve 73 denúncias contra quatro profissionais da cirurgia plástica e um médico foi denunciado 49 vezes. Em 60\% dos casos a denúncia foi feita por pessoa física.

Discussão: Foram consideradas improcedentes 17\% das denúncias e 35\% das restantes se transformaram em processos éticos ( $10 \%$ arquivados). O julgamento levou à advertência e censura em alguns casos e suspensão (5\%) e cassação do direito (3\%). Mais de 90\% dos casos anuais foram resolvidos. Conclusão. O problema tem sido abordado com eficácia e eficiência, apesar de graves imperfeições na gestão do banco de dados, que impedem análises qualitativas da questão.

Unitermos: Denúncia. Erros médicos. Processo. Sindicâncias. Dano.

\section{INTRODUÇÃO}

A evolução tecnológica permite que o homem se arrisque para além da órbita terrestre e mais, permite que o homem veja dentro de si mesmo, identifique fragmentos que compõem o seu DNA, conheça o funcionamento de seu cérebro e refaça o ser humano através da clonagem. Mesmo assim o homem adoece e está sujeito à dor, ao acidente, ao incontrolável. E quando isto acontece somente resta ao homem assim poderoso confiar em Deus, que se manifesta na ação do médico. O médico passa a ser o responsável pela salvação. E passa a ser também o responsável pelos insucessos. Estabelece-se uma expectativa de cura não fundamentada no poder resolutivo da medicina e sim baseada em uma imagem de infalibilidade que pode levar à frustração e ao desespero diante de um fracasso.

A nova postura social no Brasil, que se fundamenta em um processo de fortalecimento da cidadania, reforça os instrumentos e órgãos de defesa do consumidor e desperta nos indivíduos a noção de seus direitos. A drástica mudança na relação entre médico e paciente, decorrente dos modelos de atenção valorizados no atual sistema de saúde, minimiza a comunicação entre as partes e diluem o respeito e a admiração que eram devidos ao médico em momentos históricos anteriores. O cliente se sente com direitos iguais, enquanto o médico ainda assume posturas arrogantes baseadas na detenção do conhecimento e no status de sua profissão. E a relação se torna desigual, pois os direitos são iguais, mas os deveres não se distribuem de forma equitativa. Tal relação de poder transforma o resultado insatisfatório decorrente de um ato médico em uma insatisfação que afeta gravemente o indivíduo, levando-o ao desespero.

Aumenta, assim, o número de queixas formalizadas contra atitudes médicas, como manifestação da impotência da população diante dos agravos à saúde e diante da qualidade dos serviços que the são prestados. Motivada pelo impacto social daquelas queixas a imprensa noticia com ênfase e amplia o efeito de tal fato sem que, entretanto, existam estudos aprofundados que dêem significado aos números mencionados.

As atividades médicas implicam em interação entre pessoas. Assume-se, portanto, que a boa prática médica se caracteriza pelo equilíbrio entre o conhecimento científico, a tecnologia disponível e o relacionamento entre médico e paciente. Nem sempre, entretanto, o insucesso terapêutico está ligado à conduta do médico, devendo-se buscar o nexo de causalidade entre os eventos e identificar as possíveis causas associadas (fatores

1. Professor Adjunto da UNIFESP - Universidade Federal de São Paulo - Faculdade Paulista de Medicina, São Paulo, SP

2. Mestre em Otorrinolaringologia USP - Ribeirão Preto, SP

Rev Assoc Med Bras 2009; 55(3): 283-9 
anatômicos, fisiológicos, patológicos, sociais ou psicológicos intervenientes), de preferência de uma forma regionalizada, pois cada local apresenta características e políticas de saúde própias.

O objetivo do presente trabalho é qualificar e quantificar as denúncias apresentadas ao Conselho Regional de Medicina do estado de Goiás contra médicos.

\section{MÉtodos}

Estudo descritivo, baseado em avaliação retrospectiva feita sobre os processos registrados no Conselho Regional de Medicina do Estado de Goiás - CREMEGO, no período compreendido entre os anos 2000 e 2006.

As queixas foram agrupadas segundo a especialidade médica envolvida e o tipo de dano supostamente gerado. Desenhou-se o perfil dos reclamantes, identificando-os segundo sua natureza (pessoa física ou jurídica); o reclamado foi identificado segundo sexo, idade, procedência acadêmica e especialidade.

Os processos foram agrupados de acordo com o rito processual adotado pelo CREMEGO (denúncias autuadas, sindicâncias instaladas, processos formalizados, processos em tramitação, decisões). A avaliação atentou para as sanções decorrentes das denúncias protocoladas, da avaliação processual e das decisões formuladas.

A seleção dos indicadores se baseou na legislação, nos códigos de ética e nas normas administrativas em vigor. Utilizouse uma estratégia de avaliação ajustada a um momento de intensas transformações no exercício profissional e na vida social, visando à melhor prestação de serviços e a valorização pessoal dos médicos no exercício de sua função.

\section{Resultados}

Verificou-se que 12,3\% dos médicos inscritos em Goiás contam com mais de 60 anos de vida; $21,5 \%$ estão entre 50 e 60 anos (33,9\%, portanto, com mais de 50 anos); $21,4 \%$ entre 40 e 50 anos, ou seja, 55,3\% nasceram antes da criação da Universidade Federal de Goiás. Registram-se $26,5 \%$ entre 30 e 40 anos e $18 \%$ com menos de 30 anos.

A análise dos 4.440 registros que contém a informação necessária permitiu o agrupamento dos profissionais em 53 especialidades (Resolução CFM 1785/2006). As maiores frequências recaem sobre ginecologia e obstetrícia $(14,2 \%)$, cirurgia geral $(10,5 \%)$, medicina do trabalho, $8,4 \%)$, clínica médica $(8,2 \%)$, pediatria $(7,9 \%)$ e oftalmologia $(6,1 \%)$, cardiologia e cirurgia cardiovascular (6\%). As demais especialidades concentram menos de $6 \%$ do total em cada uma.

Os dados permitiram agrupar 2.293 denúncias segundo o motivo da queixa (76 casos sem informação), como mostra a Tabela 1.

O detalhamento das informações agrupa, com destaque sob o título de incompetência médica os casos que se referem à insatisfação com os resultados obtidos no tratamento $(56,2 \%)$, à morte do paciente $(29,4 \%)$ e ao erro diagnóstico $(10,3 \%)$. As queixas mais frequentes contra a inadequada relação entre médico e pacientes estão relacionadas com o mau atendimento $(39,5 \%)$ e negligência $(29,7 \%)$, seguindo-se extensa listagem que envolve recusa de atendimento, agressão ao paciente,

\section{Tabela 1 - Distribuição dos casos segundo 0 motivo básico das denúncias}

\begin{tabular}{lcc}
\hline Motivos & Frequência & $\%$ \\
\hline Incompetência do profissional & 724 & 31,6 \\
Inadequada relação médico/paciente & 698 & 30,4 \\
Problemas na gestão de serviços & 486 & 21,2 \\
Comportamentos incompatíveis & 385 & 16,8 \\
Total & 2.293 & 100,0 \\
\hline
\end{tabular}

omissão de socorro (frequências entre 5\% e 7\%), abuso de poder, assédio sexual, abandono, discriminação e quebra de sigilo (frequências inferiores ou iguais a $5 \%$ ).

Do total de queixas relacionadas com a gestão de serviços, destacam-se os problemas relacionados com prontuários e receitas $(43,8 \%)$ e entre os outros comportamentos incompatíveis com o exercício da profissão se destacam as questões da publicidade e da cobrança indevidas. São também frequentes as reclamações devidas às relações comerciais ou pessoais entre os profissionais médicos e de áreas afins.

A distribuição das reclamações entre os sexos privilegiou os homens ( $86 \%$ dos casos analisados).

Outra forma de ler os resultados levou ao reordenamento das 53 especialidades em 21 grupos de atividades afins, para facilidade operacional. Foi, portanto, possível se observar que o número de denúncias apresentadas contra profissionais das especialidades relacionadas com cirurgia plástica, ortopedia e traumatologia são equivalentes a mais de $50 \%$ dos profissionais daquelas especialidades. Contra profissionais das áreas de neurologia, psiquiatria e das especialidades ligadas à gineco/ obstetrícia aquele percentual ficou entre 40\% e 50\%. Agrupamse com percentuais de queixas situados entre $30 \%$ e $40 \%$ as especialidades relacionadas com a oftalmologia, a pneumologia, a oncologia e a gastroenterologia. As demais especialidades foram afetadas por denúncias em percentuais inferiores a $30 \%$ do total de profissionais inscritos (Tabela 2).

Freqüentemente um mesmo profissional é denunciado várias vezes. Um total de 805 denúncias recaiu sobre profissionais que foram acusados mais de uma e menos de cinco vezes. Os dados mostram que 38 médicos foram denunciados cinco ou mais vezes no período estudado, o que cobre 288 do total das denúncias. Analisando-se estes casos em que um mesmo médico foi acusado cinco ou mais vezes no período, percebe-se que um profissional das especialidades ligadas à cirurgia plástica foi denunciado 49 vezes; outro médico da mesma especialidade foi denunciado 14 vezes e dois outros o foram cinco vezes cada um. Houve, portanto, 73 denúncias contra quatro profissionais daquela especialidade, o que equivale a $25 \%$ das 288 denúncias registradas neste subgrupo em estudo.

Um médico foi denunciado oito vezes, alternando-se sua participação entre gineco/obstetrícia, pediatria e anestesiologia e outro foi denunciado cinco vezes por atos cometidos no exercício da ortopedia, medicina do trabalho e neurologia.

Analisando-se a procedência das denúncias percebe-se que 1.418 (60\%) foram feitas por pessoas físicas; 848 (36\%) 
foram feitas por organismos com atribuições sobre a vigilância e preservação da ética (conselho federal, conselhos regionais de medicina e comissões de ética de diversas instituições); 88 denúncias foram feitas por outros órgãos públicos ou organizações de classe (4\%) e em 13 vezes o Ministério Público foi o autor $(0,5 \%)$. Em apenas dois casos a denúncia veio de delegacias policiais.

A evolução processual mostra que foram registradas 2.369 denúncias, das quais 402 (17\%) foram arquivadas por improcedentes e 1.967 se transformaram em sindicância. Destas, 1.269 foram arquivadas e 698 se transformaram em processos éticos (35\%). Dos 698 processos (PEP) 10\% foram arquivados (69 processos), 360 já foram julgados (52\%) e 269 estão em andamento processual (38\%).

As decisões sobre os processos julgados mostram absolvição em 200 casos e 38 foram encaminhados à apreciação do Conselho Federal de Medicina. Dos 119 casos em que a denúncia foi julgada pertinente, a metade foi punida com advertência confidencial, feita em aviso reservado aos profissionais; houve censura confidencial em $27 \%$ dos casos e censura pública oficial em $15 \%$; registraram-se seis casos de suspensão por trinta dias $(5 \%)$ e três casos de cassação do direito de exercer a medicina ad referendum do CFM (2,5\%).

A Tabela 3 mostra a distribuição dos processos em andamento, segundo o ano em que foi feita a denúncia, quando se pode observar que $97 \%$ ou mais dos casos de cada ano entre 2000 e 2003 foram resolvidos; $83 \%$ dos casos do ano 2004 e entre $79 \%$ e 80\% dos casos registrados nos anos 2005 e 2006.

Das causas que levaram à aplicação de penas, a partir da denúncia inicial registrada no banco de dados, mais da metade (53\%) esteve relacionada com a morte de paciente, negligência e publicidade indevida, ainda que não tenham sido os processos analisados à luz do julgamento final.

\section{Discussão}

A nova postura social no Brasil, que se fundamenta em um processo de fortalecimento da cidadania, reforça os instrumentos (Código de Proteção e Defesa do Consumidor - CDC) e órgãos de defesa do consumidor (PROCON) e desperta nos indivíduos a noção de seus direitos protecionistas das relações de consumo tem as propostas de atender as necessidades dos consumidores, respeitarem a sua dignidade, saúde e segurança, além dos interesses econômicos, melhorando a qualidade de vida. 0 CDC veio, de forma inovadora e destemida, inverter o quadro até então existente, onde a parte economicamente mais fraca - o consumidor - tinha gigantescas dificuldades em provar os danos causados pelo empreendedor. No entanto, o legislador, diligente, criou no mesmo Código uma única exceção, qual seja, a prevista no $\S 4^{\circ}$ do artigo 14 que dispõe: a responsabilidade pessoal dos profissionais liberais será apurada mediante a verificação de culpa. Trata-se de exceção ao princípio da responsabilidade objetiva açambarcado pelo Código do Consumidor. O médico não obstante ser um prestador de serviços é, também, um profissional liberal. A relação entre médico e paciente é subordinada ao CDC mais por inércia do que por fundamentos técnico-jurídicos.
Tabela 2 - Estratificação percentual das denúncias segundo agrupamento de especialidades

\begin{tabular}{lccc}
\hline Especialidades & Especialistas & Denúncias & $\%$ \\
\hline Plástica & 217 & 139 & 64,0 \\
Ortopedia & 271 & 159 & 58,7 \\
Neuro e psiquiatria & 238 & 104 & 43,7 \\
Ginecobstetrícia & 666 & 270 & 40,5 \\
Oftalmologia & 272 & 96 & 35,3 \\
Pneumologia & 39 & 13 & 33,3 \\
Oncologia & 76 & 24 & 31,6 \\
Gastroenterologia & 116 & 36 & 31,0 \\
Pediatria & 371 & 83 & 22,4 \\
Cardiologia & 397 & 82 & 20,6 \\
Infectologia & 75 & 15 & 20,0 \\
Urologia & 256 & 48 & 18,7 \\
Otorrinolaringología & 124 & 20 & 16,1 \\
Hematologia & 40 & 5 & 12,5 \\
Medicina Trabalho & 454 & 56 & 12,3 \\
Clín. Médica & 351 & 40 & 11,4 \\
Cirurgia Geral & 498 & 53 & 10,6 \\
Endócrinologia & 144 & 10 & 6,9 \\
Medicina Intensiva & 296 & 15 & 5,0 \\
Outras & 248 & 06 & 2,4 \\
Sub-total & $\mathbf{5 . 1 4 9 *}$ & 1274 & \\
S/informação & & 1095 & \\
\hline Profissionas com mas & & &
\end{tabular}

* Profissionais com mais de uma especialidade

Tabela 3 - Distribuição do número de processos em andamento segundo 0 ano em que foi feita a denúncia

\begin{tabular}{lccc}
\hline Ano & Sindicância & $\begin{array}{c}\text { Em andamento } \\
\text { Resolvidos }\end{array}$ & \% de resolução \\
\hline 2000 & 155 & 02153 & 98,7 \\
2001 & 309 & 02307 & 99,3 \\
2002 & 337 & 05332 & 98,5 \\
2003 & 351 & 14337 & 97,0 \\
2004 & 300 & 52248 & 82,7 \\
2005 & 376 & 79297 & 79,0 \\
2006 & 461 & 93368 & 79,8 \\
Total & 2.289 & 2472.042 & 89,2 \\
\hline
\end{tabular}

Copiou-se o modelo americano, gerando a indústria do dano, que se tornou uma realidade também brasileira ${ }^{7}$.

Entendemos ser pertinentes as observações acima contidas na abordagem sob o tema em questão, citado na medida do possível as grandes transformações ocorridas na sociedade sobre direitos de cidadania e sua repercussão sobre o exercício da medicina, vez que o nosso objetivo foi a análise, quantificação e qualificação das reclamações e denúncias apresentadas ao Conselho Regional de Medicina do Estado de Goiás contra os médicos ali inscritos, no período de 2000 a 2006. Portanto, a leitura dos resultados do presente trabalho, não teve caráter defensivo nem de acusação. Funcionou como estratégia de 
avaliação necessária em momento de intensas transformações no exercício profissional e na vida social, visando a melhor prestação de serviços e a valorização pessoal dos médicos no exercício de sua função. E foi, principalmente, embasada por intensa revisão bibliográfica capaz de instrumentalizar os trabaIhos e orientar a reflexão.

Em Goiás existe uma relação aproximada de um médico para 750 habitantes, portanto dentro do recomendado pela Organização Mundial da Saúde. O perfil dos profissionais da medicina em Goiás mostra uma frequência de mais de $80 \%$ de médicos do sexo masculino, embora a situação venha sendo alterada no ingresso das novas turmas dos cursos de medicina. De um total de 2.269 denúncias, $14 \%$ recaíram sobre profissionais do sexo feminino. As denúncias incidiram significativamente, menos sobre os profissionais do sexo feminino, o que pode ser explicado pela melhor interação natural da mulher com o paciente, sua maior aplicabilidade em relação à empatia nos cuidados de saúde e sua menor participação em procedimentos de alto risco, como mostram também alguns estudos realizados no exterior ${ }^{17}$.

A informação de que $34 \%$ dos médicos tenham ultrapassado os 50 anos de idade é importante quando se pensa nos valores tradicionalmente conferidos à profissão, mas que não constituiu em fator determinante em relação ao número de denuncias, assim como não houve também, predominância em relação aos médicos jovens.

Foi significativa a flutuação na frequência da apresentação das denuncias, com evidente aumento em termos de percentuais de $297,41 \%$ das mesmas, no período compreendido entre os anos 2000 e 2006 no CREMEGO. Quando comparado com o CREMESP, ${ }^{18}$ apresentou $136 \%$ a mais de denúncias em 11 anos. O Rio de Janeiro aumentou $100 \%{ }^{19}$ e em períodos correspondentes há relatos também nos Estados Unidos e na Inglaterra de aumentos significativos ${ }^{20}$. 0 incremento médio do número de médicos registrados no CREMEGO por ano que foi de 407 registros e o incremento médio de denúncias contra os profissionais, registradas no mesmo período, foi de 304 denúncias, não justificando o aumento da denuncia com o aumento do número de médicos inscritos anualmente.

Outra justificativa para as constantes reclamações recai sobre o argumento de que a população está mais esclarecida sobre seus direitos pessoais e mais informada sobre o grande volume de indenizações pecuniárias e sanções morais impostas aos profissionais em outros países.

Dos 8.085 médicos inscritos no CRM de Goiás, 4.400 foram formados na Universidade Federal de Goiás (54\%). Dos 2.252 médicos denunciados ao CRM no período em estudo, 975 foram formados naquela universidade (43,3\%). Dos 975 formados na UFG e com denúncias no CRM do Estado contra sua atuação 710 foram formados depois do ano 1978 (73\%). Os dados parecem dizer que o peso sobre as atitudes aparentemente condenáveis não recaiu sobre a Universidade formadora e sim sobre a época em que se deu a formação. Isto reflete a postura filosófica que sinaliza os novos tempos, mas pode também a informação estar eivada de vícios relativos aos denominadores adotados, visto que o número proporcional de médicos formados depois do ponto de corte utilizado é maior do que no período anterior.
Das reclamações apresentadas pela sociedade, 49\%estão relacionadas com a qualidade do atendimento prestado em ambulatórios, hospitais ou serviços de emergência. As denúncias se apresentam como (queixas de omissão de socorro, discriminação, recusa ou mau atendimento, negligência, abandono, agressão ao paciente ou assédio sexual, quebra de sigilo ou morte do paciente). Para $25 \%$ das denúncias refere incompetência ou erro diagnóstico. Trata-se, evidentemente, de um pré-julgamento, indução a um "justiciamento", em que a sociedade geralmente aceita, sem análise prévia as notícias e comentários na fase aguda do acontecimento do motivo da denuncia, traduzindo a sua insatisfação com o tratamento, e revelando uma relação insatisfatória entre o médico e o paciente em $74 \%$ dos casos. O CREMESP mostrou que $42,4 \%$ das denúncias contra atos médicos estiveram relacionados com faltas contra a conduta da pessoa do médico, ou seja, do "homem" ${ }^{21}$. As demais queixas se referem a procedimentos relacionados com a gestão de serviços públicos ou privados, à publicidade e cobrança indevidas, abandono de plantão e condições precárias de atendimento, abuso de poder, atos ilícitos e fraudes contábeis e concorrência profissional, o que corrobora a afirmação de que a mudança na escala de valores da sociedade está se refletindo no exercício da medicina ${ }^{22}$.

Por determinação legal, o CREMEGO acolhe a denúncia feita por qualquer cidadão em desfavor dos médicos que atuam sob sua jurisdição. Tais denúncias são cartorialmente registradas, automaticamente acatadas e encaminhadas à $1^{\text {a }}$ Secretária, que após uma avaliação, solicita ou não, esclarecimentos por escrito dos denunciado, podendo ser aceitas as explicações e justificativas e julgar as denúncias improcedentes. No caso do acatamento, as denúncias são julgadas procedentes, e encaminhadas à Corregedoria de Sindicâncias, que nomeará um Conselheiro Sindicante. A sindicância se procederá dentro das normas estabelecidas pelo Código de Processo Ético Profissional. As sindicâncias, depois de instauradas e concluídas, são encaminhadas e pautadas para sessões plenárias e distribuídas em câmaras de julgamentos, que poderão ser julgadas improcedentes, procedentes ou com indicativo de uma conciliação entre denunciante(s) e denunciado(s). As sindicâncias julgadas improcedentes são arquivadas, e as julgadas procedentes são automaticamente encaminhadas à Corregedoria de Processos, para a nomeação de um Conselheiro Instrutor, e consequentemente de um Conselheiro Relator e Revisor, para posterior encaminhamento ao julgamento do Processo Ético Profissional (PEP). Aceitam-se denúncias feitas por pessoas físicas (o próprio paciente, familiares e vizinhos ou mesmo médicos e outros profissionais), ex officio pelo próprio Conselho Regional de Medicina (veiculadas pela mídia, advindas de entidades públicas, judiciário, entidades medicas, etc.), telefonemas, documentos escritos ou mensagens eletrônicas não identificadas. De 2.369 denúncias, 1.418 (60\%) foram feitas por pessoas físicas; 848 (36\%) por organismos (CREMEGO); 88 denúncias outros órgãos públicos (4\%) 13 pelo Ministério Público $(0,5 \%)$ e em dois casos a denúncia veio de delegacias policiais.

A evolução processual mostra que foram registradas 2. 369 denúncias, das quais 402 (17\%) foram arquivadas por improcedência e 1967 se transformaram em sindicância. Destas, 
1.269 foram arquivadas e 698 se transformaram em processos éticos (35\%). Dos 698 processos (PEP) 10\% foram arquivados (69 processos), 360 já foram julgados (52\%) e 269 estão em andamento processual (38\%). As decisões sobre os processos julgados mostram absolvição em 200 casos e 38 foram encaminhados à apreciação do Conselho Federal de Medicina. Em 50\% dos casos as condenações levaram à advertência confidencial em aviso reservado, à censura confidencial em $27 \%$ dos casos e à censura pública oficialem $15 \%$; seis casos de suspensão por trinta dias (5\%) e três casos de cassação do direito de exercer a medicina ad referendum do CFM (2,5\%).

Avaliação sobre o perfil e as infrações éticas profissionais dos médicos denunciados, que exercem ginecologia e obstetrícia no Estado de São Paulo, ${ }^{23}$ revelou percentual de 47,4\% de processos em fase de julgamento durante o período estudado, registrando um tempo médio de 6,2 anos como média aritmética ponderal de duração do processo. 0 estudo de Goiás mostra que a média anual de resolutividade foi de $88,5 \%$ dos processos.

O CREMESP ${ }^{24}$ relata $49,2 \%$ de condenação em processos contra médicos e indicou que a atribuição de culpa afetou $43,3 \%$ dos processos já julgados. Em Goiás indicou que os processos já julgados, em relação ao período estudado, levaram à condenação e à aplicação de penalidades em $31 \%$ dos casos analisados. Do processo de julgamento no Estado de Goiás resultaram três casos de cassação do direito de exercício da medicina, o que representa $0,4 \%$ sobre o total de PEPs instauradas, $0,8 \%$ do total de casos já examinados e 2,5\% do total de processos com avaliação condenatória da conduta profissional. O CREMESP (24) mostra 11 casos de cassação (5,3\% da amostra estudada) e em Santa Catarina, ${ }^{25}$ aponta 3,9\% de cassação do direito do exercício profissional.

No tocante às especialidades, em $45 \%$ dos casos não existem menção sobre especialidade nem área de atuação. No CREMERJ a especialidade foi registrada em apenas $22 \%$. Para otimização do processo de análise da distribuição entre as 53 especialidades e as 54 áreas de atuação reconhecidas pela Resolução CFM 1785/2006, a cirurgia plástica e a ortopedia responderam mais da metade do número de profissionais denunciados. Não se pode, entretanto, fazer uma leitura linear de tais resultados, visto que em $55 \%$ dos casos houve mais de uma denúncia contra o mesmo profissional e um cirurgião plástico sozinho foi denunciado 49 vezes. Esta constatação se confirma em matéria publicada no Boletim do CREMESP (junho de 2007), apontando a cirurgia plástica como uma especialidade que tem apresentado sérios problemas éticos.

A estratificação do percentual de denúncias em relação ao total de especialistas, nas diversas áreas, mostra que em $38 \%$ (908 casos) dos casos não se identificam as especialidades, mais de $50 \%$ das denuncias apresentadas foram contra as especialidades relacionadas com cirurgia plástica, ortopedia e traumatologia. A neurologia, psiquiatria à gineco/obstetrícia ficou entre 40 e $50 \%$. Entre 30\% e $40 \%$ agrupam-se as especialidades relacionadas com a oftalmologia, a pneumologia, a oncologia e a gastroenterologia. Inferiores a 30\% do total dos demais especialistas inscritos.

A omissão de socorro, recusa no atendimento e o abandono de pacientes somam 63 casos com indicação da especialidade, concentrando-se $19 \%$ e $17 \%$ em casos de pediatria e de gineco/ obstetrícia, respectivamente. Houve 60 casos de denúncias por agressão a pacientes e assédio sexual, dos quais 27 foram registrados sem menção de especialidade. Dos 33 casos restantes, $27 \%$ se concentraram nas especialidades de ortopedia, gineco/ obstetrícia e pediatria (com seis, três e três casos, respectivamente). Os demais se distribuíram entre as especialidades, com frequência menor ou igual a dois casos. Discute-se hoje a abordagem da denuncia sobre 0 assedio sexual, tendo em vista a complexidade da sua comprovação, vez que geralmente se passa entre quatro paredes, sem presença de testemunhas, o que dificulta em muito a sua comprovação. Das 373 acusações rotuladas como incompetência dos profissionais, foram relacionadas com a ginecologia e obstetrícia em $(30 \%)$, cirurgia plástica em (18\%), ortopedia em (12\%) e a oftalmologia (6\%). Os demais valores ficaram abaixo de $5 \%$.

As denúncias sobre relações inter-profissionais antiéticas recaíram sobre interações com as farmácias, as óticas e outros profissionais e instituições. A quebra da relação do médico com o paciente-familiares, os problemas relacionadas com outros comportamentos incompatíveis com o exercício da profissão médica e os problemas relativos gestão de serviços, foram imputadas sob alegações diversas, como insatisfação com os resultados do tratamento (407), erro diagnóstico (75), imperícia (10), imprudência (4), ausência de diagnóstico (15), mau atendimento (276), negligência (207), recusa de atendimento (49), agressão ao paciente (38), omissão de socorro (36), abuso de poder (26), assédio sexual (22), abandono (22), discriminação (16), quebra de sigilo profissional (06), publicidade indevida (124), cobrança indevida (98), problemas de relação entre médicos (42), conduta antiética (41), interação com farmacêuticos (41), interação com óticas (28), interação com instituições (7), interação com médicos (3), problemas com prontuários e receitas (213), gestão de serviços (145), abandono de plantão (46), condições precárias de atendimento (44), atos ilícitos (21), fraudes (9), perfazendo um total de 2.067 (90,14\%) denúncias, do total das 2.293 denúncias apuradas sob este agrupamento.

A questão do erro médico é um dos mais palpitantes e polêmicos assuntos em todas as camadas sociais, sendo freqüentemente tratada de forma sensacionalista pelos meios de comunicação de massa. 0 povo julga e condena com base em informações calcadas em revolta e dor (sempre presentes nos insucessos terapêuticos). Entretanto, a citação judicial de um médico por erro profissional repercute de forma contundente em sua vida pessoal e social e afeta a relação de confiança entre a população e os médicos. Impõe-se uma avaliação criteriosa dos fatores interferentes em cada ato humano, na tentativa de se chegar a uma avaliação ética ou a um julgamento moral ${ }^{26}$.

É verdade que as denúncias podem representar a não aceitação do insucesso por parte do paciente ou de seus familiares, principalmente em casos de doenças graves ou de morte. Foram 213 eventos envolvendo morte de paciente. Também é verdade, entretanto, que alguns profissionais se expõem a denúncias de forma repetida e consistente, evidenciando uma conduta inadequada. É importante ressaltar, entretanto, que o número de denúncias registradas no CREMEGO não traduz necessariamente o perfil dos seus profissionais, uma vez que os desvios de conduta 
humana se distribuem entre todas as profissões. Dos 1.075 casos de denúncias que incidiram mais de uma vez sobre o mesmo profissional, destacam-se 38 casos em que o mesmo médico foi denunciado cinco ou mais vezes no período estudado, o que cobre 288 do total das denúncias. Analisando-se estes casos em que um mesmo profissional foi acusado cinco ou mais vezes no período, percebe-se que um profissional das especialidades ligadas à cirurgia plástica foi denunciado 49 vezes, um segundo profissional foi denunciado 14 vezes e dois outros o foram cinco vezes cada um. Houve, portanto, 73 denúncias contra quatro profissionais daquela especialidade, o que se equivale a $25 \%$ das 288 denúncias registradas neste subgrupo em estudo. Convêm destacar que dois profissionais foram denunciados várias vezes em relação a comportamentos relacionados com diferentes especialidades. Um médico foi denunciado oito vezes, alternando-se sua participação entre gineco/obstetrícia, pediatria e anestesiologia e o outro foi denunciado cinco vezes, por atos cometidos no exercício da ortopedia, medicina do trabalho e neurologia. Um total de 805 denúncias recaiu sobre profissionais que foram acusados mais de uma e menos de cinco vezes.

\section{Conclusão}

Pode-se afirmar, a partir dos dados aqui analisados, que o Conselho Regional de Medicina de Goiás tem abordado o problema do erro médico com eficácia e eficiência, apesar das imperfeições na gestão do banco de dados, que limitam as análises qualitativas da questão. Foram significativas as flutuações e o crescente número das denúncias ao longo do período estudado. A evolução processual tem garantido percentuais aceitáveis de resolutividade. A gravidade dos problemas denunciados tem sido julgada e penalizada de forma similar a outros centros médicos do país. Os altos percentuais de denúncias perdem um pouco de seu significado quando se percebe a frequência em que incidem sobre os mesmos profissionais, sugerindo dificuldades pessoais mais significativas do que atitudes profissionais não compatíveis com a ética médica.

É importante o profissional atentar para o significado da relação médico-paciente com o estabelecimento de um modelo de medicina mais humanística, visando o respeito e a dignidade do paciente, proporcionando uma efetiva prevenção contra denúncias de erro profissional médico, evitando, portanto, uma série de incômodos e aborrecimentos.

É necessário melhor triagem na formação acadêmica por meio da reflexão e revisão permanentes dos preceitos éticos e humanísticos, que determinam as atitudes do homem enquanto ser social em suas relações familiares, afetivas, profissionais e políticas, nos contextos individual e coletivo, com objetivos de incorporar a consciência das dimensões biopsicossociais à formação médica e a amplitude da relação médico-paciente.

Conflito de interesse: não há

\section{SUMmarY}

A denOUNCEMENT OF MEdical ERRORS in Goiás State

OBJECTIVE. Strengthening of citizenship reinforces the instruments to defend individual rights. The health care models currently used minimize communication between doctors and patients. There has been an increasing number of formal complaints against attitudes of physicians. The social impact of these accusations is great, but studies in Brazil and in the state of Goiás are not sufficient to make them meaningful. This work was intended to quantify and qualify complaints submitted to the Regional Medical Council of the state of Goiás against medical acts.

Methods. Descriptive, retrospective study of the processes formally registered in the state of Goiás between 2000 and 2006; interpretative reading of the procedural development of filed complaintes at the Regional Medical Council of the state of Goiás and calculation of the efficacy of the ensuing actions.

RESULTS. Variation in the complaint frequency between 2000 and 2006 was not high; 62\% of complaints concerned professional incompetence and inadequate patient -physician relationship. The number of complaints regarding plastic surgery and orthopedics was significant. In $60 \%$ of cases accusations were made by individuals.

Discussion. The Regional Medical Council session resulted in warnings and reprimands in some cases, deferment (5\%), and suspension of the licence to practice medicine (3\%). Over $90 \%$ of the yearly cases were solved.

CONCLUSION. This problem has been effectively and efficiently approached, in spite of severe imperfections in data base management, preventing qualitative analyses of this matter. [Rev Assoc Med Bras 2009; 55(3): 283-9]

KEY wORDS: Denouncement. Medical errors. Process. Dentistry

\section{REFERÊNCIAS}

1. Pereira MGA, Azevedo ES. A relação médico-paciente em Rio Branco/AC sob a ótica dos pacientes. Rev Assoc Med Bras. 2005;51:153-7.

2. Neves MP. Thomas Percival: tradição e inovação. Bioética 2003;111:11-22.

3. Gomes JCM, França GV. In: Erro Médico. Um Enfoque Sobre Sua Origem E Suas Conseqüências. Montes Claro: Unimontes; 1999.

4. Santo Neto LL. O erro diagnóstico. S-Brasília Médica. 1997;34:44-6.

5. Campos RAC, Camargo, ERA, Fróes O, Ganança MM. Elementos do biodireito. Acta ORL. 2005;23:6-16.

6. Gil H. In: Revista de Derecho Procesal Civil, Publicación Ibero-Americana en Filipinas, n. 2 1957, p.357 apud Eduardo Pallares. Derecho procesal civil, $2^{a}$ ed, México: Editorial Porrua, 1965.

7. Couto Filho, AF, Souza AP. Responsabilidade civil médica e hospitalar: repertório jurisprudencial por especialidade médica: teoria da eleição procedimental; iatrogênia. Belo Horizonte: Del Rey; 2001. p.37-46.

8. Guarnier V. Nuevas tecnologías y nuevos daños iatrogénicos. Gaceta Médica de México 1995;131:533-51.

9. Teixeira H, Dantas F. O bom médico. Rev Bras Educ Med. 1997;21:43-6.

10. Ismael JC. O médico e o paciente: breve história de uma relação delicada. São Paulo: T. A. Queiroz Editor; 2002.

11. Sá Jr. LSM. Evolução no conceito de ética médica. Medicina. 2001;127:32-6.

12. Goic A. El fin de la medicina. Santiago: Editorial Mediterráneo; 2000.

13. Varaldo C. Convivendo com a hepatite C. $2^{a}$ ed. [citado 26 set 2007]. São Paulo: Editora: Mauad; 2003.

14. Rogers C, Stevens B. De pessoa para pessoa: o problema de ser humano. 4a ed. São Paulo: Pioneira; 1991.

15. Vilardell F. Problemas éticos de la tecnología médica. Bol Of Sanit Panam. 1990;108:399-404.

16. Barbieri JE. A Responsabilidade civil do M sob a óptica da bioética [dissertação]. Franca: Faculdade de História, Direito e Serviço Social, Universidade Estadual Paulista Júlio de Mesquita; 2006.

17. Taragin MI, Wilczek AP, Karns ME, Trout R, Carson JL. Physician demographics and the risk of medical malpractice. Am J Med. 1992;93:537-42. 
18. Camarin L. In: Boletim do CREMESP. 238; jun 2007.

19. Falcão MSSA. A ética médica e suas infrações: um estudo sobre os processos ético-profissionais do Estado do Rio de Janeiro. Rio de Janeiro: Escola Nacional de Saúde Pública, 1993.

20. Maia DB. Erro médico no Brasil: análise de processos ético-profissionais julgados pelo Conselho Federal de Medicina no período de 1988 a 1998 [monografia]. São Luís: Universidade Federal do Maranhão; 1999.

21. Fortes PAC. A responsabilidade médica nos tribunais [tese]. São Paulo: Faculdade de Saúde Pública, Universidade de São Paulo; 1994.

22. Udelsmann A. Responsabilidade civil, penal e ética dos médicos. Rev Assoc Med Bras. 2002;48:172-82.

23. Boyaciyan K. O perfil e as infrações ético-profissionais dos médicos denunciados que exercem Ginecologia e Obstetrícia no Estado de São Paulo [tese]. São Paulo: Universidade Federal de São Paulo, Escola Paulista de Medicina; 2005

24. Moraes IN. Erro médico e a lei. $3^{a}$ ed. São Paulo: Editora Revista dos Tribunais; 1995.

25. D’Ávila, RL. O comportamento ético-profissional dos médicos de Santa Catarina: uma análise dos processos disciplinares do período de 1958 a 1996. Florianópolis: UFSC; 1998.

Artigo recebido: 05/12/07 Aceito para publicação: 29/11/08 